\title{
ISOLAMENTO, AUTENTICAÇÃO E SELEÇÃO DE RIZÓBIOS ISOLADOS DE ADESMIA
}

\author{
Rafael Goulart Machado ${ }^{1 *}$, Enilson Luiz Saccol de Sá ${ }^{2}$, Murilo Dalla Costa $^{3}$, Gilberto Dall Agnol ${ }^{3}$, Suélen Oldra ${ }^{4}$, Vanessa Silva ${ }^{4}$ \\ ${ }^{1}$ Doutorando, PPG Ciência do Solo da Universidade Federal do Rio Grande do Sul, 91540-000, Porto Alegre, Brasil. \\ 2 Professor, PPG Ciência do Solo da Universidade Federal do Rio Grande do Sul, 91540-000, Porto Alegre, Brasil. \\ 3 Pesquisador, Empresa de Pesquisa Agropecuária e Extensão Rural de Santa Catarina - Epagri, 88502-970, Lages, Brasil. \\ ${ }^{4}$ Bolsista de Iniciação Científica, PPG Ciência do Solo da Universidade Federal do Rio Grande do Sul, 91540-000, Porto Alegre, \\ Brasil.
}

*E-mail: rgoulartmachado@gmail.com

Recebido em: $24 / 07 / 2015$

Aceito em: 24/09/2015

\section{RESUMO}

A adesmia (Adesmia latifolia) é uma leguminosa nativa da região sul do Brasil, que apresenta algumas características de crescimento e adaptação interessantes para o seu cultivo como espécie forrageira. O objetivo do presente trabalho foi isolar, identificar e autenticar rizóbios infectivos e eficientes quanto à fixação biológica de nitrogênio em adesmia. Com base em características morfo-fisiológicas foram isoladas e identificadas colônias com características rizobianas. Também foram estudadas três estirpes recomendadas para adesmia (SEMIA 3007, SEMIA 6437 e SEMIA 6438), e 50 rizóbios isolados de A. latifolia, fornecidos pela Epagri-SC. Foram obtidos 17 isolados bacterianos. No experimento para autenticação observou-se que do total de rizóbios estudados, 61 isolados foram capazes de nodular adesmia e 38 foram capazes de incrementar a massa fresca das plantas. As plantas inoculadas com os isolados EEL462 10 e EEL1010 superaram as do tratamento Controle + $\mathrm{N}$ e as inoculadas com a estirpe SEMIA6437 na produção de massa fresca total, número de folhas e comprimento da parte aérea.

Palavras-chave: Fixação Biológica de Nitrogênio (FBN). Simbiose. Adesmia latifolia. Pastagem Nativa.

\section{Introdução}

O gênero Adesmia contém mais de 230 espécies e é amplamente distribuído em regiões áridas do Chile, Argentina, Bolívia, Peru, sul do Brasil e Uruguai [1]. Atualmente são conhecidas 17 espécies deste gênero nativas do sul do Brasil [2].

Em experimentos conduzidos em casa de vegetação, tem sido observado que plantas da espécie Adesmia latifolia se destacam pela maior exuberância de folhas, acúmulo de biomassa aérea, teor de proteína bruta, hábito estolonífero e capacidade para fixação simbiótica de nitrogênio do que outras espécies do mesmo gênero [2]. A espécie A. latifolia é tolerante a diferentes doses de alumínio, o que não é observado com $A$. tristis [3]. Esta tolerância está relacionada à adaptação da $A$. latifolia a solos ácidos, característicos do Rio Grande do Sul, e é um importante potencial a ser explorado. Tendo estas características de produtividade e adaptabilidade desejáveis a uma espécie forrageira, a A. latifolia pode constituir uma importante alternativa para o suprimento proteico a bovinos leiteiros ou bovinos de corte.
Juntamente com a A. tristis, a A. latifolia está entre as mais estudadas, porém os estudos sobre seu potencial forrageiro ainda estão na fase preliminar, com poucos dados sobre desempenho no campo [4]. Ao mesmo tempo, é relatada na literatura a escassez de estudos de nodulação simbiótica de espécies do gênero Adesmia, bem como de outras leguminosas nativas $[5 ; 6]$.

Há relatos de dificuldades no estabelecimento inicial da $A$. latifolia a campo, devido à concorrência com espécies espontâneas como o azevém [7]. Neste sentido, é de fundamental importância para a maior competitividade desta leguminosa nativa em sistemas de cultivo o isolamento e a seleção de rizóbios eficientes quanto à fixação biológica de nitrogênio (FBN). Rizóbios eficientes quanto à FBN em adesmia, além de proporcionar uma vantagem adaptativa à leguminosa com relação a outras espécies que venham a competir por nutrientes, resultarão em menores custos com fertilizantes nitrogenados minerais.

Visto que bactérias diazotróficas possuem diferentes níveis de eficiência na FBN, o objetivo do presente do trabalho 
foi autenticar isolados previamente obtidos de nódulos e rizosfera de A. latifolia, bem como estudar em condições in vitro a capacidade destes isolados de estimular o crescimento de plântulas comparativamente a tratamentos controle e estirpes atualmente recomendadas para a espécie.

\section{Metodologia}

Foram coletadas amostras de solo rizosférico, situado imediatamente abaixo dos estolões de crescimento vegetativo das plantas de adesmia, desde a superfície do solo, até uma profundidade de aproximadamente $15 \mathrm{~cm}$. Também foram coletadas plantas inteiras de adesmia (Adesmia latifolia). Foram realizadas coletas nos municípios de Correia Pinto-SC e Eldorado do Sul-RS. O georeferenciamento dos locais de coleta foram os seguintes: Correia Pinto-SC (Latitude:27³8`35,60“', Longitude: $50^{\circ} 20^{\prime} 04,48^{\prime \prime}$ e Altitude de $855 \mathrm{~m}$ ); Eldorado do Sul-

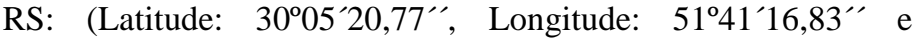
Altitude de $37 \mathrm{~m}$ ).

As plantas de adesmia coletadas inteiras foram separadas em laboratório em parte aérea e radicular e cuidadosamente lavadas em água corrente, para posterior destacamento dos nódulos. Os nódulos foram destacados, secos em papel toalha e acondicionados em frascos de vidro, com sílica e algodão para preservação, conforme descrito por [8]. Para a obtenção de nódulos a partir das amostras de solo, foi realizada a inoculação com uma suspensão de $50 \mathrm{~g}$ de solo em $100 \mathrm{~mL}$ de água destilada estéril. Foram adicionadas alíquotas de $10 \mathrm{~mL}$ da suspensão dos solos amostrados em plântulas de adesmia cultivadas em vasos de Leonard [9], com volume de $650 \mathrm{~mL}$. As plântulas foram obtidas de sementes previamente escarificadas com lixa $\mathrm{n}^{\circ} 100$ por 1 minuto, desinfestadas por imersão das sementes em álcool (70\%) por 30 segundos, seguido de hipoclorito de sódio (2,5\%) por 30 segundos e sete lavagens consecutivas com água destilada esterilizada em autoclave a $120^{\circ} \mathrm{C}$ por 20 minutos, sendo em seguida armazenadas à temperatura ambiente $\left(20\right.$ a $\left.25{ }^{\circ} \mathrm{C}\right)$ por 24 horas para germinação.

As plântulas foram colocadas em vasos de Leonard [9] com vermiculita e areia $(2: 1)$, com solução nutritiva Sarruge a $25 \%$ [10], em casa de vegetação. A inoculação com as suspensão das amostras de solo foi realizada quando as plantas estavam com sete dias de emergência e com um a três pares de folhas. A inoculação foi feita adicionando-se $2 \mathrm{~mL}$ da suspensão de solo por vaso. Aos 45 dias após a inoculação, efetuou-se coleta das plantas, separando-se a parte aérea do sistema radicular. Após lavagem das raízes, os nódulos obtidos em casa de vegetação foram destacados, secos em papel toalha e acondicionados em recipientes de vidro, com sílica e algodão.

\subsection{Maceração dos nódulos e obtenção de isolados}

Os isolados foram reidratados por 24 horas, em água destilada estéril e mantidos no refrigerador até o dia seguinte.
Após a reidratação, os nódulos foram macerados separadamente em tubo de ensaio estéril, com bastão de vidro esterilizado, em câmara de fluxo laminar. A suspensão do nódulo macerado foi inoculada em placas de petri com meio de cultura sólido levedura-manitol com corante vermelho congo (LMV) [9], utilizando-se o método da gota [11] e do espalhamento [12], separadamente.

As placas foram incubadas em estufa a $28{ }^{\circ} \mathrm{C}$ sendo examinadas diariamente com o auxílio de uma lupa estereoscópica. Os isolados bacterianos com colônias com características morfológicas persistentes eram inoculados em outras placas, de modo a se obter colônias puras com morfologia persistente. No final do procedimento foram obtidos 17 isolados bacterianos purificados, listados na tabela 1 .

Tabela 1. Relação dos isolados obtidos, com os respectivos municípios de origem e as formas de coleta.

\begin{tabular}{lll}
\hline Isolado & Localidade & Forma de Coleta \\
\hline UFRGS A11 & Eldorado do Sul & Nódulos \\
UFRGS Al2 & Eldorado do Sul & Nódulos \\
UFRGS Al3 & Eldorado do Sul & Nódulos \\
UFRGS Al4 & Eldorado do Sul & Nódulos \\
UFRGS A15 & Eldorado do Sul & Amostra de Solo \\
UFRGS A16 & Eldorado do Sul & Nódulos \\
UFRGS A17 & Eldorado do Sul & Nódulos \\
UFRGS A18 & Eldorado do Sul & Nódulos \\
UFRGS A19 & Eldorado do Sul & Nódulos \\
UFRGS A110 & Eldorado do Sul & Nódulos \\
UFRGS Al16 & Eldorado do Sul & Nódulos \\
UFRGS Al17 & Eldorado do Sul & Amostra de Solo \\
UFRGS Al18 & Eldorado do Sul & Amostra de Solo \\
UFRGS Al19 & Correia Pinto & Amostra de Solo \\
UFRGS Al20 & Correia Pinto & Amostra de Solo \\
UFRGS A121 & Correia Pinto & Amostra de Solo \\
UFRGS Al22 & Correia Pinto & Amostra de Solo \\
\hline & & \\
\hline
\end{tabular}

\subsection{Caracterização Morfológica dos isolados}

Os rizóbios estudados foram caracterizados morfologicamente em placas de petri, com meio de cultura levedura-manitol com vermelho congo (LMV) [9]. Foram avaliadas características referentes ao tamanho, cor, elevação, diâmetro, consistência e opacidade da colônia.

Após a caracterização fenotípica, cada cultura de rizóbios foi inoculada em três tubos de ensaio, contendo meio LMV [9]. 
Estes tubos inoculados foram armazenados na Coleção de Culturas de Rizóbios da UFRGS.

\subsection{Experimento de autenticação e seleção}

Todos os isolados estudados foram submetidos à avaliação da capacidade de formar simbiose com a planta hospedeira, em um experimento de autenticação. Foram avaliados quanto à capacidade de induzir a formação de nódulos em plantas de adesmia os 17 isolados obtidos com a purificação em placa e 50 rizóbios isolados de adesmia, fornecidos pela Empresa de Pesquisa Agropecuária e Extensão Rural de Santa Catarina (Epagri-SC) e as estirpes SEMIA 3007, SEMIA 6437 e SEMIA 6438, atualmente recomendadas pelo ministério da agricultura, pecuária e abastecimento (MAPA) para a produção de inoculantes para adesmia, que foram fornecidas pela Coleção de Culturas de Rizóbios da Fundação de Pesquisa Agropecuária do Rio Grande do Sul (FEPAGRO).

Para efeito de comparação, foram conduzidos dois tratamentos controle não inoculados, um controle sem inoculação não recebeu a adição de $\mathrm{N}$ mineral (Controle - $\mathrm{N}$ ) e o outro $($ Controle $+\mathrm{N})$ recebeu a adição de alíquota de solução de $\mathrm{NH}_{4} \mathrm{NO}_{3}\left(20 \mathrm{~g} \mathrm{~L}^{-1}\right)$, equivalente à aplicação de $100 \mathrm{~kg} \mathrm{de} \mathrm{N} \mathrm{ha}^{-1}$.

$\mathrm{O}$ estudo foi realizado in vitro, em condições de laboratório, utilizando-se tubos de ensaio de $30 \mathrm{~mL}$, contendo uma tira de papel toalha e $15 \mathrm{~mL}$ de solução nutritiva Sarruge a $25 \%$ [10], esterilizados em autoclave a $120{ }^{\circ} \mathrm{C}$ por 20 minutos. Em cada tubo foi adicionada uma semente pré-germinada de adesmia, com o auxílio de uma pinça flambada e em câmara de fluxo laminar. Um dia após, os tubos foram inoculados, em câmara de fluxo laminar, com a adição de $1 \mathrm{~mL}$ de caldo de cultura de cada um dos isolados. Para a produção do inóculo, os rizóbios foram crescidos em tubos de ensaio com tampa de rosca, contendo meio de cultura LM liquido [9] e colocados em incubador orbital a $28{ }^{\circ} \mathrm{C}$ com agitação de $120 \mathrm{rpm}$ por sete dias. O inóculo utilizado apresentava concentração celular de $10^{8}$ unidades formadoras de colônias por $\mathrm{mL}$ (ufc. $\mathrm{mL}^{-1}$ ), observada conforme metodologia descrita por [13]. Após a inoculação, os tubos foram tampados com buchas de algodão e colocados em lampadário com 8 horas de luz por dia, à temperatura ambiente.

$\mathrm{O}$ experimento foi composto por 72 tratamentos e três repetições, sendo 70 tratamentos inoculados com os rizóbios estudados e dois tratamentos controle não inoculados: um tratamento com adição de $\mathrm{N}$ mineral (Controle $+\mathrm{N}$ ) e outro sem $\mathrm{N}$ mineral (Controle - N). Após 35 dias, as plantas foram coletadas, sendo quantificadas: a massa fresca total das plantas, o número de folhas e de nódulos e o comprimento da parte aérea e da raiz.

\section{Resultados e discussões}

$\mathrm{Na}$ figura 1, são apresentadas frequências das características fenotípicas dos rizóbios isolados no presente estudo.

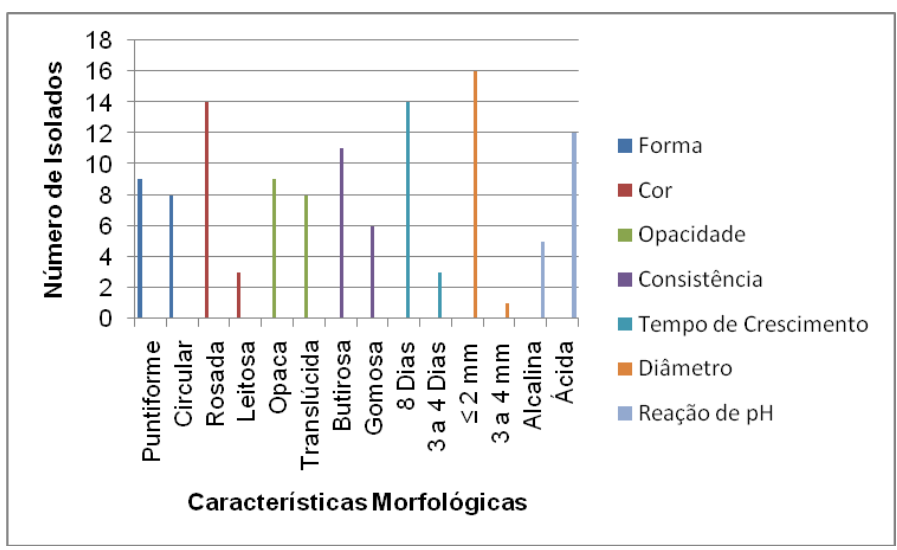

Figura 1: Gráfico de frequência de isolados de Adesmia latifolia, para as características morfológicas estudadas.

Além das características apresentadas na figura 1, todos os rizóbios isolados de adesmia obtidos no presente estudo apresentaram colônias convexas e com bordas regulares, típicas de colônias de rizóbios. As características de forma, cor, opacidade, consistência, tempo de crescimento, diâmetro e reação ao pH são típicas de rizóbios, sendo que 14 isolados com colônias menores que $2 \mathrm{~mm}$ após oito dias de incubação apresentaram características fenotípicas de Bradyrhizobium sp., enquanto outros três isolados, com colônias de 2 a $4 \mathrm{~mm}$ após quatro dias de incubação apresentaram características morfológicas que podem ser relacionadas ao gênero Mesorhizobium.

Foi observada a formação de nódulos radiculares em 61 diferentes tratamentos, sendo considerados rizóbios estes isolados presentes nas inoculações que induziram nodulação. Os primeiros nódulos radiculares surgiram de 7 a 12 dias após a inoculação e os isolados EEL46210; EEL1010 e UFRGS A19 foram os de nodulação mais abundante ao final dos 35 dias, com médias de 6,7; 4,3 e 5,7 nódulos por planta, respectivamente. Por outro lado, a SEMIA 3007 e a SEMIA 6438, atualmente recomendadas para a composição de inoculantes para adesmia, apresentaram baixa nodulação: média de apenas 1,0 e 0,3 nódulo por planta, respectivamente. Devido às diferentes nodulações observadas nos 70 diferentes tratamentos, infere-se que é de fundamental importância a etapa de seleção inicial de rizóbios em ambientes axênicos como os do presente estudo, pois devido à presença da população de rizóbios nativos em condições de campo, esta diferenciação quanto à capacidade de nodulação pode ser mascarada. 
Subsequentemente à formação dos nódulos observada a partir do sétimo dia após inoculação, passa a ocorrer o processo de fixação biológica de nitrogênio $(\mathrm{FBN})$, executado pela enzima nitrogenase. Neste processo, ocorre a quebra das moléculas de gás atmosférico $\left(\mathrm{N}_{2}\right)$, e o subsequente fornecimento do nutriente nitrogênio $(\mathrm{N})$ à leguminosa simbionte, após transformação do gás $\mathrm{N}_{2}$ em $\mathrm{NH}_{3}$, assimilável pelas plantas [14]. Em contrapartida, a planta fornece ao rizóbio proteção e carboidratos fotoassimilados, que permitem a sobrevivência dos rizóbios no interior dos nódulos.

Dos 70 isolados observados, 38 foram capazes de incrementar o rendimento de adesmia em ao menos um dos parâmetros avaliados. Os isolados EEL46210 e EEL1010, obtidos de nódulos de Adesmia latifolia, coletados no município de Lages-SC e gentilmente cedidos pela Epagri-SC, induziram os melhores resultados em relação à massa fresca total de plantas (MFT), número de folhas (NF) e comprimento da parte aérea (PA). Estes isolados (EEL46210 e EEL1010) foram superiores ao Controle $+\mathrm{N}$, que recebeu dose de $\mathrm{N}$ equivalente a $100 \mathrm{~kg}$ N.ha ${ }^{-1}$, apresentando, respectivamente, $54 \%$ e $25 \%$ maior massa fresca total e $76 \%$ e $72 \%$ maior comprimento de parte aérea. Também superaram a SEMIA 6437, a SEMIA com melhor desempenho no presente estudo, quanto à massa fresca total e ao comprimento da parte aérea. A inoculação com o rizóbio UFRGS A19, obtido no presente estudo a partir de nódulos de adesmia provenientes de Eldorado do Sul, também produziu massa fresca total e número de folhas superiores ao Controle $+\mathrm{N}$, bem como maior massa fresca total que as plantas inoculadas com a estirpe SEMIA6437. Com os resultados, infere-se que os rizóbios EEL46210 e EEL1010, provenientes de Lages, bem como o isolado UFRGS A19, originário de Eldorado do Sul, surgem como importantes alternativas para futuros estudos de inoculação em adesmia (A. latifolia) em escala mais ampla, primeiramente em casa de vegetação e posteriormente a campo.

Os isolados EEL46210, EEL1010 e UFRGS A19 produziram a maior quantidade de nódulos e induziram os mais significativos incrementos quanto aos parâmetros de rendimento avaliados. Por estes terem sido todos obtidos pelo processo de maceração de nódulos destacados de raízes de adesmia coletadas a campo, infere-se que o processo de maceração de nódulos induziu o isolamento de rizóbios mais eficientes comparativamente ao processo de obtenção de rizóbios da rizosfera. Outras características destes isolados de melhor desempenho é a morfologia típica do gênero Mesorhizobium sp., enquanto outros de menor eficiência apresentaram características típicas do gênero Bradyrhizobium sp.

A grande eficiência dos isolados EEL46210, EEL1010 e UFRGS A19 sob as condições do presente estudo, revela uma perspectiva otimista para próximos estudos, onde deve-se verificar a manutenção deste alto rendimento em condições menos isoladas, como ambientes de casa de vegetação e a campo, nos quais estes rizóbios serão submetidos a maiores adversidades de sobrevivência ao ambiente e de competição com outras bactérias por espaço no sítio de infecção radicular.

Em um grupo intermediário, porém com bom rendimento quanto aos parâmetros avaliados, estão os isolados EEL16010B, EEL47310, UFRGS Al2 e UFRGS Al3. Os tratamentos inoculados com estes rizóbios apresentaram massa fresca total equivalente ao Controle $+\mathrm{N}$, porém o superaram quanto ao número de folhas e comprimento da parte aérea e superaram também as plantas inoculadas com a SEMIA 6437 quanto ao comprimento da parte aérea. Outros 11 isolados também apresentaram nodulação, tiveram algum destaque quanto aos parâmetros avaliados, porém no presente estudo estão em um nível inferior de rendimento. São os casos dos isolados EEL48910, EEL45610, EEL 0811, EEL 1711, EEL 45210, EEL 45410, EEL 44810, EEL 4010, EEL4110, UFRGS A17 e UFRGS Al8.

As plantas inoculadas com a estirpe SEMIA 6437 apresentaram rendimento satisfatório, superando as do tratamento Controle $+\mathrm{N}$ quanto à massa fresca total e ao número de folhas, além de boa nodulação. Com os presentes resultados, infere-se que a estirpe SEMIA 6437 manteve sua capacidade de nodulação e de incrementar o rendimento de adesmia, mostrando-se viável e eficiente para composição de inoculantes para a espécie estudada.

Nove isolados foram incapazes de nodular adesmia sob as condições do presente estudo. Apesar de apresentarem características de morfologia colonial semelhante a colônias de rizóbios em meio de cultura, não confirmaram a característica de formar simbiose compatível em adesmia, sendo, portanto, descartados. Outros 23 isolados induziram a formação de nódulos em raízes de adesmia, porém não incrementaram a massa fresca total das plantas em comparação com o tratamento Controle - N. Apesar de induzirem a formação de nódulos, o que representa um custo fisiológico para a planta, estas bactérias não foram capazes de incrementar a massa fresca total. Isto indica que muitos dos nódulos contabilizados não foram eficientes em fixar o $\mathrm{N}$ (nitrogênio) atmosférico e assim os custos fisiológicos destas nodulações não foram convertidos em aumento de rendimento das plantas.

Por outro lado, os três isolados mais eficientes, perante um universo de 70 isolados estudados, representam proporcionalmente $4 \%$. Extrapolando esta proporcionalidade para cultivos de leguminosas, se configura como uma grande evidência a necessidade de se re-inocular as leguminosas cultivadas com estirpes comprovadamente eficientes, para se aumentar a proporção na rizosfera de bactérias eficientes e assim maximizar a probabilidade de nodulação das raízes por bactérias selecionadas e com boa capacidade de promover o crescimento das plantas.

$\mathrm{Na}$ figura 2 é apresentado um gráfico de frequência referente aos parâmetros de eficiência observados nas plantas de adesmia, inoculadas com os 70 diferentes isolados. [6 - 15] 
também estudaram a nodulação de A. latifolia por rizóbios, bem como a eficiência da interação planta/bactéria quanto ao incremento do rendimento desta espécie. Ambos os autores verificaram boa nodulação, porém baixa eficiência quanto ao incremento da massa seca da parte aérea, comparativamente ao tratamento controle com adição de nitrogênio mineral.

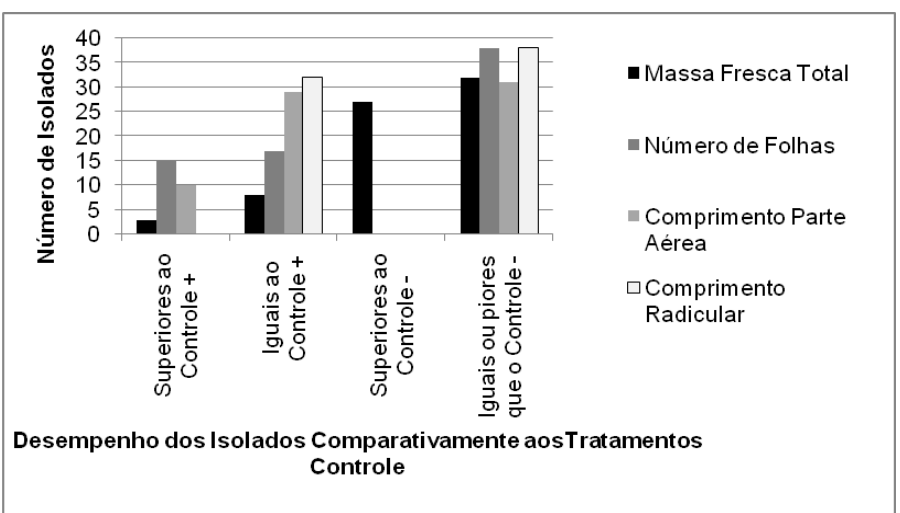

Figura 2. Gráfico de frequência para o desempenho dos isolados de adesmia, comparativamente aos tratamentos Controle, quanto aos parâmetros massa fresca total, número de folhas, comprimento da parte aérea e comprimento radicular de plantas de adesmia (Adesmia latifolia). Significância de 5\%, pelo teste de Scott Knott.

Os parâmetros apresentados na figura 2 foram avaliados comparativamente aos tratamentos Controle + e Controle -, podendo-se observar que dos 70 isolados estudados, três superaram o Controle + quanto à massa fresca total, 15 quanto ao número de folhas e 10 quanto ao parâmetro comprimento da parte aérea.

De acordo com [16], em cultivos de leguminosas a campo, a nodulação é fruto de uma competição entre os rizóbios presentes no solo e os inoculados. Os nódulos podem ser formados por bactérias nativas e pouco eficientes ou bactérias eficientes veiculadas através de inoculantes. Com isto, nem sempre a estirpe recomendada e veiculada através do inoculante, é a que forma os nódulos. Por este motivo, é essencial o investimento em trabalhos de isolamento e seleção de rizóbios simbiontes, competitivos e eficientes na fixação de $\mathrm{N}$ atmosférico, bem como a re-inoculação periódica da estirpe recomendada, para se manter alta a probabilidade de infecção da planta pelo rizóbio selecionado para a cultura em questão. Neste sentido, do grupo de 70 rizóbios testados no presente estudo, destacam-se dois com grande potencial para futura composição de inoculantes para A. latifolia. Sob as condições do presente estudo, os rizóbios EEL46210 e EEL1010 mostraram-se superiores às estirpes liberadas para A. latifolia (SEMIAS) e surgem como possíveis alternativas para a composição de inoculantes comerciais para esta leguminosa nativa.

\section{Conclusões}

Dentre os 70 isolados estudados, 61 foram capazes de nodular Adesmia latifolia, sendo 38 eficientes em estimular o crescimento das plantas.

Os isolados EEL46210, EEL1010 e UFRGS A19 são os mais promissores quanto ao crescimento e desenvolvimento de A. latifolia e apresentam características morfológicas típicas do gênero Mesorhizobium sp.

\section{ISOLATION, AUTHENTICATION AND SELECTION OF ADESMIA RHIZOBIA}

ABSTRACT: The adesmia (Adesmia latifolia) is a native legume from southern Brazil, which presents some growth characteristics and interesting adaptation for its cultivation as forage species. The objective of this study was to isolate, identify and authenticate infective and efficient rhizobia for adesmia. Based on morphological and physiological characteristics colonies with rhizobial features were isolated and identified. Three lineages recommended for adesmia (SEMIA 3007, SEMIA 6437 and SEMIA 6438), and 50 rhizobia isolates from A. latifolia, provided by Epagri-SC were also studied. 17 bacterial isolates were obtained. In the experiment for authentication, 61 strains were able to nodulate adesmia and 38 were able to increase the plants total fresh mass. Plants inoculated with EEL46210 and EEL1010 isolated exceeded the Control $+\mathrm{N}$ treatment and SEMIA6437 treatment for the parameters total fresh mass, leaf number and shoot length.

Keywords: Biological Nitrogen Fixation (BNF). Symbiosis. Adesmia latifolia. Native Pasture.

\section{Referências}

[1] BURKART, A. Las leguminosas argentinas silvestres y cultivadas.Buenos Aires: ACME Agency. 1952. 596p.

[2] SCHEFFER-BASSO, S.M. et al. Disponibilidade e valor nutritivo de forragem de leguminosas nativas (Adesmia DC.) e exóticas (Lotus L.).Revista Brasileira de Zootecnia, v. 30, p. 975982, 2001.

[3] SCHEFFER-BASSO, S.M., et al. Crescimento de plântulas de Adesmia spp. submetidas a doses de alumínio em solução nutritiva.Revista Ciência Rural, v. 30, p. 217-222, 2000.

[4] SCHEFFER-BASSO, S.M.; VENDRUSCOLO, M.C.; CECCHETTI, D. Desempenho de leguminosas nativas (Adesmia) e exóticas (Lotus, Trifolium) em função do estádio fenológico no 
primeiro corte. Revista Brasileira de Zootecnia, v. 34, p. 18711880, 2005.

[5] SCHEFFER-BASSO, S.M.; CARNEIRO, C.M. \& VOSS, M. Nodulação e fixação biológica de nitrogênio em Adesmia araujoi Burk. Revista Brasileira de Agrociência, v. 6, p. 16-18, 2000.

[6] MUNIZ, A.W. Promoção do crescimento em adesmias e macieira utilizando rizóbios de Adesmia latifolia. 2011. 85 p. Tese (Doutorado) - Programa de Pós-Graduação em Microbiologia Agrícola e do Ambiente, Universidade Federal do Rio Grande do Sul, Porto Alegre, 2011.

[7] SCHEFFER-BASSO, S.M. et al. Comportamento de leguminosas (Adesmia, Lotus, Trifolium) em mistura com festuca.Revista Brasileira de Zootecnia, v. 31, p. 2197-2203, 2002.

[8] XAVIER, G.R. et al. Protocolo operacional cultivo de plantaisca para isolamento de rizóbio a partir de nódulo de planta-isca. Seropédica: Embrapa Agrobiologia, 1997. 7p.

[9] VINCENT, J.M. Manual for the practical study of root nodule bacteria. Oxford: Blackwell Scientific, 1970. 164p.

[10] SARRUGE, J.R. Soluções nutritivas. Summa Phitopathologica, Piracicaba, v. 1, p. 231-234, 1975.

[11] MILES, A.A. \& MISRA, A.A. The estimation of the bacterial power of blood.Journal of Hygiene, London, v. 3, p. 732-749, 1988.

[12] BUCK, J.D.; CLEVERDON, R.C. The spread plate as a method for the enumeration of marine bacteria. Limnology and Oceanography, v. 5, p. 78-80, 1960.

[13] MOURA, R.A. et al.1987. Técnicas de laboratório. Atheneu, Rio de Janeiro.

[14] TAIZ, L. \& ZIEGER, E. Fisiologia vegetal. $3^{\circ}$ ed., Porto Alegre: Artemed, 2004, 719 p.

[15] SCHEFFER-BASSO, S.M. et al. Nodulação e Fixação biológica de nitrogênio em Adesmia latifolia e Lotus corniculatus em vasos de Leonard. Revista Brasileira de Zootecnia, v. 30, p. 687-693, 2001.

[16] DREW, E. et al. Inoculating legumes: a practical guide. 1st. ed. Kingston: Grains Research and Development Corporation (GRDC), 2012. $71 \mathrm{p}$. 